required to be filled by gentlemen of your profession, is of such character as to justify any considerable experimentation of that plan. In other words, I believe the influences which surround political selection for public office, either by ballot boxes or appointment of the executive, are such as would not get a high class of public experts, and therefore I am convinced that aside from the suggestion that $I$ have made, that in each case there should be the designation by the court of the experts who should examine into that case and make a report, we ought not to go any further. (Applause.)

\section{WHY ALL PHYSICIANS SHOULD BE PRE- PARED FOR SURGICAL EMERGENCIES.}

Read before North Texas Medical Association, at Denison, Texas, Dec. 8, 1896.

BY J. E. GILCREEST, M.D. GAINESVILLE, TEXAS.

It has long been a question of no small importance to me, why all physicians do not carefully prepare themselves for surgicad emergencies; and especially does that query apply to men who practice in the remote villages, or in the country. where they will certainly be called to attend all accidents occurring in the immediate vicinity. For the older membrs, who have had the benefit of experience, there is no excuse. For the younger men who are just starting ont, there may be possibly, but I doubt it, gentlemen, seriously doubt it. While we have many noble, conservative, earnest and capable young men in the profession, men who will shine in the scientific firmament, we still have two extremes: 1, the bold ones, who are overanxious to wield the scalpel and thus roll up a large list of surgical operations, the results of which are more or less cautiously exposed; 2, the timid young men, who make a bad break in the very outset of their professional career, by quieting their consciences with the delusion that they will not be called upon to do any surgery, that they do not fancy it as a science, and consequently think it wholly unnecessary to go to any trouble or expense in preparation. The men comprising the first class are dangerous. With an eye single to reputation, they will rush blindly into an operation, without paying any attention to the minor details, so all-important in the successful treatment of recent wounds. They think more of the skilful use of the scalpel or saw, than of the preparation of those very useful instruments; study more about how nice they could do this amputation, or that resection, than how to dress and care for it properly, after its execution. They can very easily find occasion to operate, where the conservative surgeon could not possibly have done so. In short, if they do not curb their false ambition, these men will sacrifice many human lives in order to glorify themselves, and like a sky-rocket, will go on and up, until the explosion, in shape of some glaring blunder, comes, when their descent will be equally rapid, and remorse alone is all that is left to them.

And now we shall investigate those of the second class. The man who enters the ranks of professional life with an idea that he already knows enough for all practical purposes, would do well to commit suicide, for it will prevent him from doing murder indirectly. This class, if possible, is worse than the former, because people very naturally suppose that they at least understand the simpler details, and in consequence depend upon them to do the thing most necessary until more experienced help can, when required, be summoned. What is the result? They are wholly unprepared. Their gray matter is a muddle and won't work. They get rattled. Everything they do only serves to make matters worse, and so hopelessly upset things generally, that it is sometimes impossible for the very best surgeon to correct the blunders which, taken with the original trouble, end seriously, if not fatally. Now, there is no excuse for all this. Any man can and should qualify himself to cleanse and dress wounds aseptically and antiseptically. The expense is nothing, really nothing, and the rules are easy to comprehend; true, they are strict, yet simple. Let us see what would be necessary for each physician to do, and have, to treat wounds successfully. First, he should spend a few hours in studying up the aseptic and antiseptic treatment of wounds from some recent text-book on surgery. If he has none, he should borrow one long enough for that. He will need in a small bag scalpel, scissors, dissecting and artery forceps and probe, ten yards bichlorid gauze in a sealed jar, bandages, absorbent cotton, antiseptic catgut and silk in bottles, a few needles, a box of green soap, brush and fountain syringe, some bichlorid solution or tablets. The cost of this need not be more than three or four dollars, and with it, it is possible to put nearly all recent wounds in an aseptic condition. But to return to our men. We would not expect a student of the fine arts, the first time he took up his brush or chisel, to execute a painting like the famous Raphael, or to design and execute a masterpiece in statuary like the immortal Angelo. But by careful study of the most minute details, he can and will master his work, if he keeps everlastingly at it. The same is true of surgery. It has its elementary rules, its fundamental principles, and to ever be successful, we must learn them as thoroughly as a child does its alphabet. The following language emanated, I think, from Sir Isaac Newton, just after the famous discovery which will carry his name in reverence among the learned of all future ages. "For I seemed to have been only a child playing on the seashore, diverting myself by now and then finding a smoother pebble or a prettier shell, while the great ocean of truth lay all undiscovered before me." Think of it! "Only a child." A man whose life entire had been given up to the study of science. The language is worthy the modesty of a great and learned philosopher. Such has been the experience of all men who have achieved either ordinary success, or eternal fame; all of them have been close adherents to the most minute details. Now, the first principles of surgery are those of aseptic and antiseptic preparation, dressing and treatment of wounds, recent or otherwise. Once we have this mastered, and can properly execute all points scientifically, we have then a solid foundation laid whereupon a substantial surgical edifice can be builded, against which the storms of time or adversity can beat with all the relentless fury of enraged nature, and there stand, a lasting monument to the man who built as he went. We want no pyrotechnic displays, nothing but simple, earnest, honest, conscientious, hard work. We can not afford to either experiment, or treat with dalliance, the human family. Such is not our mission, and when we do so, we become not only professionally insincere and dishonest, but sin before the most high God of the universe, and to Him will be held responsible for any wrong done in cold-blooded experimental work, or from wilful ignorance; and most ignorance, in this nineteenth century, is little else than wilful. 
Let us take the matter to our own rooftree. Suppose parent, wife or child should receive an injury, which of itself had it received proper care, amounted to nothing. One of these "don't-want-to-know" men is called, with his untrimmed finger nails, beneath which several generations of different bacteria have been allowed to thrive unmolested for many days. The wound we will presume to be nearly, if not quite, aseptic. How long do you suppose it will remain so under the following conditions? He very carefully gets a kitchen wash-pan, fills it from the tea-kettle, finds after cautiously inserting his dirty fingers therein, that it is too hot, slaps his hands against a pair of not over-cleaned pantaloons until the pain subsides, cools the water from an ordinary kitchen bucket, with great deliberation and care drops four minims of carbolic acid into the pan, and his antiseptic preparation is completed. $\mathrm{He}_{\theta}$ quietly tip-toes back to the injured one, looks very wise and the real trouble begins. He pays little or no attention to the broken and bruised pieces of flesh that, at best are of such low vitality as to offer no resistance whatever, but rather serve as an ideal pabulum for the bacteria. He gets a piece of cloth of doubtful origin, immerses it in his solution, squeezes a little water over the injured parts, pokes it once or twice with a dirty probe, binds it up with a piece of "nice soft old sheet" and his work is done. The wound is now thoroughly infected; it suppurates most beautifully; trouble follows; possibly death. Now this man may be called, and probably is, a thorough conscientious physician; but I maintain, that he is responsible for that death beyond any question. And while the law protects him, he is certainly guilty of an ignorance of those details which would have surely prevented all this, hence, is culpable, and ought to be punished. Here is a fact that is true beyond question. In medicine we often meet with indifferent results as to their action physiologically; but in wound treatment there is none of that uncertainty. Good work is always productive of good results. There are many lives lost annually from a lack of this knowledge, and no man is excusable, who has had time and opportunities to qualify himself for this work. The antiseptic method of wound treatment, has, like all good things, been the subject of ridicule by some men, but without cause. It has stood the test thus far, and will continue to do so. Last year Henle wrote a timely and important paper on the antiseptic treatment of recent wounds. He took up the laboratory study of streptococcus infection. The germs were obtained from erysipelas and phlegmons occurring in the human system and were inoculated in the ears of guinea pigs. In some cases they were rendered excessively virulent by a successive series of inoculation, the spleen pulp of animals dead of streptococcus infection being injected into another, the reenforcements being continued. The results showed that the application of bichlorid solution prevented the develment of erysipelas. The ear which was not so treated but simply cleaned with water, after thiriy or forty hours, became red, swollen and infiltrated, presenting all the symptoms of local erysipelas, while microscopic section showed wide diffusion of the germs. The dis. infected ear remained normal, without reaction, saving that which comes from the healing of a clean wound. Microscopic section revealed a complete absence of germs. Beginning with disinfection carried out a few minutes after infection of the wound, and length- ening the intervals, he found that if bichlorid be employed three hours after infection, even through the most virulent form of streptococcus be inoculated the wound remains reactionless. In some cases where cleansing was not attempted for eight hours, erysipelas did not develop, or if it did, was more mild and slow in its course. Microscopic section showed that the first four hours the germs remained strictly localized. After that, they begin to penetrate the lymph spaces, and were found at some distance from the surface of the wound, hence beyond the action of the most powerful disinfectants. The clinical application of these facts is very clear, as to the value of antiseptic treatment of recent wounds. It has been demonstrated by laboratory research; and to be effected, must be applied as early as possible after the infliction of the wound, and must penetrate to its deepest part; there should be no hesitancy in enlarging the wound when necessary to allow thorough applications to all its parts. But even if the wound be two, or three, or even four hours old; the surgeon by this treatment may hope to avoid suppuration. Now, gentlemen, if wounds that are septic from their manner of infliction and exposure, can be rendered aseptic, why can not all practitioners, by a few hours' study and preparation, cleanse and put a fresh wound in an aseptic condition? For my part, I can see no reasonable excuse. He can do so if he will; and after having rendered that valuable service, can if he does not care to close the wound or take any further surgical responsibility, dress the wound with plenty of moist bichlorid gauze, cover with rubber tissue, retain the whole by bandage, and keep the wound in good condition for any operation that may be necessary; but unless the work is carried out in every detail, it may as well not be done at all. I could mention a number of cases, that have come under my observation the past few years, where lives and limbs have been lost, that might have been saved by strict antiseptic treatment. Doubtless the majority of the association have had similar experiences, so I will not consume your valuable time by reporting them.

THE RADICAL CURE OE HYDROCELE BY A NEW AMBULATORY METHOD.

BY J. N. BARTHOLOMEW, B.S., M.D.

PROFESSOR OF SURGERY, WEST SIDE POST-GRADUATE SCHOOL AND POLICIINIC; PROFESSOR OF SURGICAL ANATOMY, COLLEGE OF PHYSICIANS AND SURGEONS: CONSULTING SURGEON TO THE WOMAN'S CHARITY HOSPITAL, CHICAGO.

The tendency of modern surgery is toward methods that shorten convalescence as much as is compatible with safety and toward ambulatory treatment when possible. As far as I have been able to ascertain no satisfactory ambulatory treatment of hydrocele by any radical method has been described. The nearest approach to it being the old method by injection, which in many instances is far from satisfactory. I wish here very briefly to detail a method of treatment that has been put to the test in a few cases with very gratifying results.

Before describing this method I wish to review briefly the operations that have been most used and are usually employed today; to point out some of the deficiencies of these methods and contrast them with the procedure I am about to describe. In speaking of hydrocele I refer to an abnormal accumulation of fluid in the tunica vaginalis testis, the pathology of which is so well known that it need not here be referred 